\title{
Capturing daily assessments and home treatment of congenital hemophilia with inhibitors: design, disposition, and implications of the Dosing Observational Study in Hemophilia (DOSE)
}

\author{
This article was published in the following Dove Press journal: \\ Journal of Blood Medicine \\ 6 November 2012 \\ Number of times this article has been viewed
}

\author{
Guy Young' \\ Caitlyn T Solem ${ }^{2,3}$ \\ Kate Hoffman ${ }^{4}$ \\ Jenna Kabawat ${ }^{4}$ \\ A Simon Pickard ${ }^{3}$ \\ Robert Z Gut ${ }^{5}$ \\ David L Cooper ${ }^{5}$ \\ 'Children's Center for Cancer and \\ Blood Disorders, Children's Hospita \\ Los Angeles, Los Angeles, CA, \\ ${ }^{2}$ Pharmerit, Bethesda, MD, ${ }^{3}$ Center \\ for Pharmacoeconomic Research, \\ University of Illinois at Chicago, \\ Chicago, IL, ${ }^{4}$ Outcome Sciences, \\ Cambridge, MA, ${ }^{5}$ Novo Nordisk Inc, \\ Princeton, NJ, USA
}

Objective: The daily recordings of treatment by patients with congenital hemophilia with inhibitors and their caregivers were assessed as part of the Dosing Observational Study in Hemophilia (DOSE) to understand the patterns of bypassing agent use and health-related quality of life.

Methods: Frequently bleeding patients prescribed recombinant activated factor VII as first-line therapy were eligible. Participants recorded daily paper diaries for at least 90 days and until at least four bleeding episodes had occurred. Web-based entry was optional. Assessment included bleeding status, work or school day status, bleeding episode, treatment, impact on planned activities, and health-related quality of life.

Results: Diaries were completed by 18 adults and 19 caregivers ( 21 children). A total of 4063 diary days and 194 bleeding episodes over 491 bleed days were recorded. A small proportion of diary days were bleed days $(8.2 \%)$ or treatment days $(8.2 \%)$. Half the bleed days were not planned work or school days for patients (53\%) or caregivers (48\%). An exact agreement was observed between electronic and paper records for $93 \%$ of the reviewed health-related quality of life measurements.

Conclusion: Daily diary completion by patients and caregivers is feasible and provides insight into the impact of congenital hemophilia with inhibitors on daily activities and overall quality of life. Positive participation and completion rates were supported by frequent patient contact made by independent patient support liaison personnel.

Keywords: daily assessment, recombinant activated factor VII, rFVIIa, NovoSeven, quality of life

\section{Introduction}

Congenital hemophilia $(\mathrm{CH})$ is a rare disease resulting from a deficiency of coagulation factor VIII in patients with hemophilia A (CHA) or of factor IX in patients with hemophilia B (CHB). Approximately 18,000 individuals in the United States have been diagnosed with $\mathrm{CH} .{ }^{1}$ The standard treatment is replacement of the deficient coagulation factors; however, alloantibodies/inhibitors to factor replacements develop in $15 \%$ to $30 \%$ of CHA patients and in $3 \%$ to $5 \%$ of CHB patients. ${ }^{2,3}$ Currently, there are approximately 800 known $\mathrm{CH}$ patients with inhibitors (CHwI) in the United States.

The presence of inhibitors in $\mathrm{CH}$ patients often results in greater difficulty in controlling bleeding episodes as well as frequent bleeding into joints, which leads
Correspondence: Guy Young Children's Hospital Los Angeles 4650

Sunset Blvd, Mail Stop 54

Los Angeles, CA 90027, USA

$\mathrm{Tel}+\mathrm{I} 32336 \mid 5507$

Fax + I $32336 \mid 4628$

Email gyoung@chla.usc.edu 
to arthropathy, pain, and disability. Treatment for bleeding episodes in these patients is different from that for other $\mathrm{CH}$ patients since standard factor replacement is not effective. Acute bleeding episodes in CHwI patients are managed with bypassing agents, such as recombinant factor VIIa (rFVIIa) (NovoSeven ${ }^{\circledR}$ RT, Novo Nordisk A/S, Bagsvaerd, Denmark) and plasma-derived activated prothrombin complex concentrate (FEIBA VH ${ }^{\circledR}$, Baxter AG, Vienna, Austria), rather than with factor replacements. Treatment is also more complex in $\mathrm{CHwI}$ than in $\mathrm{CH}$ patients, who usually receive only one or two doses of replacement coagulation factors for each bleeding episode. In contrast, CHwI patients may require multiple doses over several days to resolve a single bleeding episode.

Although treatment for bleeding episodes is administered intravenously, nearly all treatments are given in the home setting. Furthermore, regimens are often based on a combination of physician recommendations and the experience of the patient and caregiver. Consequently, actual treatment patterns and their impact on CHwI patients and their families are largely unrecorded and poorly understood.

Patient diaries are useful tools for collecting patientreported information about disease condition, treatment, and health-related quality of life (HRQoL). Daily diary assessments have been conducted in a variety of conditions, often focusing on a specific aspect of patient-reported outcomes, such as functional impairment, symptoms, or wellbeing. Among these studies, a small but growing number have incorporated HRQoL measures into daily diaries; ${ }^{4-9}$ however, few studies have evaluated daily HRQoL using generic measures such as the EQ-5D, from which a profile of health and index-based utility scores are generated. Despite the availability of many stand-alone handheld diary devices and Web-based diaries, published evidence that informs the use of these measures via electronic data capture is limited, particularly in CHwI patients.

The objective of the Dosing Observational Study in Hemophilia (DOSE) was to facilitate our understanding of how rFVIIa and other coagulation factor products are used in CHwI patients prescribed first-line rFVIIa in the home setting, ${ }^{10}$ the patient/caregiver decision-making process around bleed recognition and treatment; ${ }^{11}$ and the impact on HRQoL ${ }^{12}$ and associated patient-centered issues, such as interference with work or school, time spent by the patient or caregiver administering the medication, and other major interference with the daily activities of the patient or caregiver. As the patient/caregiver reported data in this study are quite extensive and are being reported in detail elsewhere, ${ }^{10-12}$ the purpose of this article is to evaluate the feasibility of the daily collection of these treatment outcomes as reported by CHwI patients or their caregivers, identify the key methodological issues related to study completion, provide overall descriptions of the relevant populations being assessed, and discuss the general limitations and applications of this approach that are consistent across all analyses.

\section{Methods \\ Ethics}

The study was conducted in accordance with the Declaration of Helsinki and its amendments in force at the initiation of the study ${ }^{13}$ as well as the Guidelines for Good Pharmacoepidemiology Practice. ${ }^{14}$ It was conducted with prior approval by local institutional review boards and with written consent from the participants or their legal representatives. The participants were compensated for their contribution to the study, with additional compensation for those directly entering data in real time into the electronic diary format.

\section{Study population}

Patients with CHA or CHB with inhibitors who had at least four bleeding episodes of any type in the prior 3 months and who were prescribed rFVIIa as the first-line treatment or as the recommended therapy for bleeding episodes (including prescribed rFVIIa therapy for breakthrough bleeding on immune tolerance therapy [ITT] or prophylaxis) were eligible for the study. Patients were consented and enrolled by study sites after screening against inclusion/exclusion criteria, and then were trained and provided diaries. In parallel to patient enrollment, sites reported on patient demographics, hemophilia history, and current prescriptions.

\section{Study design}

The study was conducted from January 2008 to July 2009 at 20 study sites in the United States, all of which were federally designated hemophilia treatment centers. The patients or their caregivers participated in the diary study for at least 90 days and until patients experienced at least four bleeding episodes.

\section{Daily diary}

The daily diary was developed in association with health care professionals (eg, physicians and nurses), CHwI patients, and caregivers who all provided insight into categorical responses for all descriptive fields to minimize free-text fields. Daily diary assessments recorded information on bleeding status, interference with planned activities, and QoL assessments 
(EQ5D-3L, visual analog scale [VAS] health, VAS pain) (Table 1). Permission was obtained from the EuroQol Group to use the standard EQ5D-3L (index score and VAS health) on a daily basis. Additional information was recorded on the days a patient had a bleeding episode or reported ongoing treatment for bleeding, even if the bleeding episode had already ended. Specifically, details of bleeding episodes, bypassing treatment administered, time spent mixing and administering agents, pain levels at the time of each dose, and HRQoL information were recorded on bleed forms (Table 1). Absenteeism from planned daily activities was measured by the percentage of missed or unproductive bleed days that occurred on scheduled work or school days for the participant, as reported in the daily diary entries. The study participants were encouraged to save and submit the bar codes from box tops of bypassing agents used to validate diary reporting by verifying that the dose reported correlated with product use.

Primary diaries were kept on paper. Additional Internetbased entry was optional. Electronic diaries were submitted online in real time, whereas paper diaries were submitted monthly to the dedicated patient support liaison personnel at the contract research organization. The standardized $10 \mathrm{~cm}$
VAS was used in the paper diaries and was transferred to the electronic diaries as a number. Paper-only diaries were entered into electronic diary format by the contract research organization.

\section{Patient and caregiver support}

Throughout the study, independent dedicated patient support liaison personnel provided logistical support to the patients and their caregivers, and contacted them regarding training, data clarification, overdue forms, product box tops, and additional bleed forms.

\section{Data validation}

Data validation was performed throughout the study by comparing electronic diaries with paper diaries (for participants who recorded both), comparing product box tops with bleed diaries, making telephone or email contact with participants, and reviewing paper diaries for inconsistencies.

Because Web-based entry of VAS health scores as an integer on a $0-100$ scale had not been validated, a preplanned comparison of the reported VAS on the $10 \mathrm{~cm}$ scale, with the number reported, was performed. For $53 \%$ of diary days with electronic EQ-5D VAS assessments, correlations

Table I Information recorded in the daily diary and bleed day diary assessments

\begin{tabular}{|c|c|}
\hline Daily diary assessments & Bleed day diary assessments (bleed forms) \\
\hline $\begin{array}{l}\text { Bleed status } \\
\text { - Started } \\
\text { - Stopped } \\
\text { - Continued }\end{array}$ & $\begin{array}{l}\text { Details of the bleeding episode } \\
\text { - Bleed identification } \\
\text { - Cause } \\
\text { - Location } \\
\text { - Type of bleed } \\
\text { - Time of bleed onset and resolution } \\
\text { - Reasons for considering that a bleeding episode had stopped }\end{array}$ \\
\hline $\begin{array}{l}\text { Work or school day status (Yes or No) } \\
\text { - Patient work or school day } \\
\text { - Caregiver work day }\end{array}$ & $\begin{array}{l}\text { Details of bypassing treatment administered } \\
\text { - Reasons for initiation of treatment } \\
\text { - Reasons for dose and dose interval selection } \\
\text { - The number of vials of bypassing agent used on an hour-by-hour basis } \\
\text { - Overall subjective assessment at time of each dose } \\
\text { - Effectiveness, dosage, and number of recombinant activated factor VII doses used } \\
\text { - Duration of mixing and infusion time for each agent at each infusion }\end{array}$ \\
\hline $\begin{array}{l}\text { Optional EQ-5D assessments } \\
\text { - Mobility } \\
\text { - Self-care } \\
\text { - Daily activities } \\
\text { - Pain and discomfort } \\
\text { - Anxiety and depression }\end{array}$ & $\begin{array}{l}\text { Activity interference assessment } \\
\text { - Lost patient or caregiver school or work time } \\
\text { - Changes to patient's or family's planned activities }\end{array}$ \\
\hline $\begin{array}{l}\text { Visual analog scale scoring of } \\
\text { - Overall health } \\
\text { - Overall pain }\end{array}$ & Details of concomitant pain medications used \\
\hline Family anxiety and stress rating & $\begin{array}{l}\text { Pain assessment } \\
\text { - At baseline } \\
\text { - At each dose }\end{array}$ \\
\hline Family planned activity interference assessment & \\
\hline
\end{tabular}


between paper- and Web-based responses were manually analyzed to determine any discrepancies between the two diary platforms.

\section{Results}

\section{Patient disposition}

Fifty-two patients (25 pediatric, 27 adult) were enrolled (Table 2), representing 7\% of the approximately $800 \mathrm{CHwI}$ patients in the United States. The historical use of rFVIIa to control acute bleeding by the enrolled patients included on-demand treatment (37 patients), control of breakthrough bleeds while on bypassing agent prophylaxis (10 patients), control of breakthrough bleeds while on ITT (three patients), and control of breakthrough bleeds while on ITT or bypassing agent prophylaxis. ${ }^{2}$ As expected, ITT was more common in the pediatric population; prophylaxis was also more common in this group. The median duration of study participation was 91 days. This was similar for both caregiver-completed diaries for pediatric patients (91 days) and for adult patients (108.5 days) (Table 3). Analysis of patient histories provided by the study sites in parallel with patient enrollment revealed two patients prescribed plasma-derived activated prothrombin complex concentrate as first-line therapy and two patients with a history of less than four bleeds in the past year.

\section{Patient support and communication}

Each participant was contacted by email or telephone at least once weekly by the dedicated patient support liaison personnel. There were 758 communications (average 15 contacts per participant) in total, with the majority (624 contacts [82\%]) made during the diary entry period (Table 4).

\section{Diary completion and diary days}

Diaries were completed by $75 \%$ (39/52) of the enrolled participants (19 caregivers on behalf of 21 pediatric patients, 18 adult patients), resulting in a total of 4063 diary days (Tables 2 and 5). Enrolled pediatric patients included two sets of siblings whose diaries were reported by their caregivers. Adult patient-reported diary days accounted for 2059 total diary days and caregiver-reported diary days accounted for 2004 total diary days. There were 3776 potential diary days for patients and caregivers who opted in to track daily HRQoL evaluations.

Twenty-three (59\%) participants completed both paper and electronic diaries, resulting in 2529 (62\%) paper-andelectronic diary days. Both patients and their caregivers completed more paper-and-electronic diaries than paper-only diaries (Table 5).

\section{Bleed days}

Only a small proportion of the diary days were bleed days (mean/median per patient: 13.9\%/8.2\%) (491 bleed days; 194 bleeding episodes) or treatment days (mean/median per patient: $13.1 \% / 8.2 \%)$. The majority of these bleeds were spontaneous (57.4\%) and located in the joint (69.7\%) for all the treatment groups (Table 6). Only one patient completing a diary did not experience a bleeding episode during the study

Table 2 Patient disposition

\begin{tabular}{|c|c|c|c|c|}
\hline & \multicolumn{3}{|c|}{ Treatment group } & \multirow[t]{2}{*}{ All } \\
\hline & On demand & ITT & Prophylaxis & \\
\hline Enrolled patients ${ }^{\mathrm{a}}$ & 37 & $5^{\mathrm{a}}$ & $12^{\mathrm{a}}$ & 52 \\
\hline - Pediatric (age $\leq 18)$ & 13 & 4 & 10 & 25 \\
\hline - Adult (age > 18) & 24 & 1 & 2 & 27 \\
\hline Diary completers ${ }^{\mathrm{b}}, \mathrm{n}$ (\% of enrolled) & $24(64.9)$ & $5(100.0)$ & $12(100.0)$ & $39(75.0)^{c}$ \\
\hline - Pediatric (age $\leq 18$ ) & 9 & 4 & 10 & 21 \\
\hline - Adult (age > 18) & 15 & 1 & 2 & 18 \\
\hline Patients with bleeding episodes, $\mathrm{n}$ (\% completers) & $23(95.8)$ & $5(100.0)$ & $12(100.0)$ & $38(97.4)$ \\
\hline - Pediatric (age $\leq 18)$ & 8 & 4 & 10 & 20 \\
\hline - Adult (age > I8) & 15 & 1 & 2 & 18 \\
\hline Patients with daily HRQoL assessments, $\mathrm{n}$ (\% completers) & $22(91.7)$ & $5(100.0)$ & $12(100.0)$ & $37(94.9)^{c}$ \\
\hline - Pediatric (age $\leq 18$ ) & 7 & 4 & 10 & 19 \\
\hline - Adult (age > 18) & 15 & 1 & 2 & 18 \\
\hline Patients who completed 90 study days, n (\% completers) & $20(83.3)$ & $4(80.0)$ & $8(66.7)$ & $31(79.5)$ \\
\hline - Pediatric (age $\leq 18$ ) & 7 & 3 & 7 & 16 \\
\hline - Adult (age > I8) & 13 & 1 & 1 & 15 \\
\hline
\end{tabular}

Notes: ${ }^{\mathrm{T} T w o}$ enrolled patients had used both ITT and prophylaxis; ${ }^{b}$ the diaries of adult patients were self-completed, whereas the diaries of pediatric patients were completed by their caregivers; 'includes one patient with less than four bleeds in the past year.

Abbreviations: aPCC, activated prothrombin complex concentrates; HRQol, health-related quality of life; ITT, immune tolerance therapy 
Table 3 Study duration and proportion of bleed and treatment days for diary completers ${ }^{\mathrm{a}}$

\begin{tabular}{|c|c|c|c|c|c|c|}
\hline & \multicolumn{3}{|c|}{ Treatment regimen } & \multicolumn{2}{|c|}{ Patient age } & \multirow[t]{2}{*}{ All } \\
\hline & On demand & ITT & Prophylaxis & $\begin{array}{l}\text { Pediatric } \\
(\text { age } \leq 18)\end{array}$ & $\begin{array}{l}\text { Adult } \\
(\text { age }>18)\end{array}$ & \\
\hline \multicolumn{7}{|c|}{ Study duration per patient (days) } \\
\hline Number of patients & 24 & 5 & 12 & 21 & 18 & 39 \\
\hline Mean (SD) & II $3.7(33.6)$ & $90.2(1.3)$ & $92.8(16.9)$ & $97(23.0)$ & II $5.5(33.8)$ & $105.5(29.6)$ \\
\hline Median & 95 & 91 & 91 & 91 & 108.5 & 91 \\
\hline IQR & $90-137$ & $90-91$ & $83.5-95$ & $90-91$ & $90-|4|$ & $90-124$ \\
\hline Range & $74-180$ & $88-91$ & $66-124$ & $74-180$ & $66-180$ & $66-180$ \\
\hline \multicolumn{7}{|c|}{ Proportion of bleed days (\%) } \\
\hline Number of patients & 24 & 5 & 12 & 21 & 18 & 39 \\
\hline Mean (SD) & $10.5(10.5)^{*}$ & $30.2(25.6)$ & $15.7(12.5)$ & $15.7(16.0)$ & $11.8(13.3)$ & $13.9(14.8)$ \\
\hline Median & 6.5 & 26.1 & 9.5 & 8.9 & 5.9 & 8.2 \\
\hline IQR & $3.9-13.3$ & $24.2-26.4$ & $6.0-27.4$ & $6.6-24.2$ & $3.0-17.4$ & $3.9-24.2$ \\
\hline Range & $0.0-41.1$ & $2.2-72.2$ & I.I-37.9 & $0-72.2$ & $0.7-4 I .1$ & $0.0-72.2$ \\
\hline \multicolumn{7}{|c|}{ Proportion of treatment days (\%) } \\
\hline Number of patients & 24 & 5 & 12 & 20 & 18 & 38 \\
\hline Mean (SD) & $8.5(8.8)$ & $30.2(25.6)$ & $17.3(13.6)$ & $15.7(16.2)$ & $10.1(12.9)$ & I3.I (14.8) \\
\hline Median & 6.5 & 26.1 & 8.9 & 8.9 & 3.3 & 8.2 \\
\hline IQR & $2.7-11.7$ & $24.2-26.4$ & $6.6-26.6$ & $6.6-25.2$ & $2.2-14.1$ & $3.3-16.7$ \\
\hline Range & $0.0-34.4$ & $2.2-72.2$ & $2.0-45.5$ & $0-72.2$ & $0.7-45.5$ & $0.0-72.2$ \\
\hline
\end{tabular}

Notes: $* P=0.0058$ for mean percentage of bleed days for the on-demand only group vs mean percentage of bleed days for the ITT group; ${ }^{a}$ the diaries of adult patients were self-completed, whereas the diaries of pediatric patients were completed by their caregivers.

Abbreviations: ITT, immune tolerance therapy; IQR, interquartile range; SD, standard deviation.

period (Table 2). Patients in the on-demand group reported a smaller proportion of bleed days and bleed treatment days than did patients in the ITT and prophylaxis groups (Table 3). Adult patients reported a smaller proportion of bleed days and treatment days than did children (Table 3 ).

\section{Quality of life}

Quality-of-life assessments, including EQ5D-3L, VAS health, and VAS pain (Table 1), on both bleeding and nonbleeding days were completed by 37 of 39 enrolled patients (Table 2) for 3771 of the 3776 eligible diary days completed by these patients or their caregivers ( 472 bleed days and 3299 non-bleed days). Half the bleed days recorded in this study were not planned work or school days for all patients (53\%) and caregivers (48\%), and therefore, were not eligible to be classified as being missed or unproductive.

There was an exact agreement between electronic and paper records for $93 \%$ of the EQ-5D VAS scores reviewed. The remaining scores were within either $1 \mathrm{~mm}$ or $2 \mathrm{~mm}$ above ( $5 \%$ of VAS scores) or below ( $2 \%$ of VAS scores) the actual measurement.

\section{Discussion}

The congenital hemophilia inhibitor patient population is very small, both in the United States and globally. Hence, the opportunities for collecting information directly from

Table 4 Communications between patient liaison personnel and patients/caregivers

\begin{tabular}{|c|c|c|c|}
\hline & Paper diaries & Web diaries & Total \\
\hline \multicolumn{4}{|l|}{ All communications } \\
\hline Total calls/emails/communications per patient communications & 326 & 432 & 758 \\
\hline Mean & 16.3 & 14.46 & 15.23 \\
\hline Median (range) & $12(3-4 \mid)$ & $13(2-35)$ & $13(2-4 \mid)$ \\
\hline \multicolumn{4}{|l|}{ Communications before start of diaries } \\
\hline Total calls/emails/communications per patient communications & 59 & 75 & 134 \\
\hline Mean & 2.95 & 2.39 & 2.63 \\
\hline Median (range) & $2(0-12)$ & $2(0-13)$ & $2(0-13)$ \\
\hline \multicolumn{4}{|l|}{ Communications after start of diaries } \\
\hline Total calls/emails/communications per patient communications & 267 & 357 & 624 \\
\hline Mean & 13.35 & 12.07 & 12.6 \\
\hline Median (range) & $10(2-39)$ & II (I-27) & II (I-39) \\
\hline
\end{tabular}


Table 5 Diary days completed by study participants

\begin{tabular}{llll}
\hline & $\begin{array}{l}\text { Caregiver } \\
\text { diaries }^{\text {a }}\end{array}$ & $\begin{array}{l}\text { Adult } \\
\text { diaries }\end{array}$ & All \\
\hline Number of diary responders & & \\
Number of diary patients & 19 & 18 & 39 \\
Paper-only diary days & 21 & 18 & \\
Paper and electronic diary days & 839 & 695 & 1443 \\
Total diary days & 1165 & 1364 & 2620 \\
\hline
\end{tabular}

Notes: ${ }^{a}$ Two sets of siblings had diaries reported by their caregivers; ${ }^{b}$ responders refer to the adult patients and caregivers of pediatric patients who completed the study diaries.

patients are limited to some extent. As treatment has shifted to a home treatment paradigm, the need for an information flow from patients to their physicians and other caregivers has become more urgent. Furthermore, the extensive experience of patients and caregivers in managing their disease is a wealth of information that could benefit the advancement of treatment in this therapeutic area and inform clinical decision making in practice. Patient-reported diaries could be a useful addition to the comprehensive care that these patients receive from their hemophilia treatment centers; however, in practice, available paper or electronic bleed logs are poorly adhered to and poorly maintained by hemophilia patients. ${ }^{15}$ Daily assessments of HRQoL could also provide valuable data useful in interpreting clinical trial outcomes and generating quality-adjusted life-year data for economic evaluations.

A first step toward the widespread use of electronic data capture of patient-centered outcomes in hemophilia is gathering of evidence to support its feasibility, validity, and reliability. The diaries reported in this study showed that categorical data did not capture all the necessary information from the diary responder. Handwritten comments in the margins of the paper diaries indicated that allowances must be made in the diaries for unforeseen circumstances, such as overlapping bleeding episodes or prophylaxis doses on days of acute bleeding.

The electronic reporting platform was used by two-thirds of the responders. The ability to perform real-time tracking and the assistance that responders could receive using this medium may have contributed to its high usage. While the majority of responders were clearly comfortable using the electronic diary, access to the Internet may still be a limitation for some patients. Alternative solutions could include the use of independent Internet-accessible devices (eg, smart phones) or Internet-enabled tablets (eg, netbooks).

No major difficulties were encountered by the study participants regarding the completion of the questionnaires on QoL and interference with work or school. Excellent agreement between the paper and electronic versions of the VAS scale was observed, which suggests that the different modes of data collection may be interchangeable without a loss of reliability in these patients. Daily HRQoL assessments appeared to be feasible and may improve the accuracy of the information obtained, given the infrequency of bleed days observed in this study. Periodic assessments would likely have resulted in sampling only the baseline in this population. In contrast, daily HRQoL provided significant new insight into daily issues, both at baseline and during bleeding episodes. Another important aspect of the evaluations of absences

Table 6 Causes and types of bleeding episodes

\begin{tabular}{|c|c|c|c|c|}
\hline & On demand & ITT & Prophylaxis & All patients \\
\hline Number of patients & 23 & 5 & 12 & 38 \\
\hline Total number of bleeds & 101 & 58 & 59 & 194 \\
\hline \multicolumn{5}{|l|}{ Cause of bleed, $n(\%)$} \\
\hline Number of bleeds & 97 & 58 & 57 & 188 \\
\hline Spontaneous & $55(56.7)$ & $24(4 I .4)$ & 42 (73.7) & $108(57.4)$ \\
\hline Trauma & $31(32.0)$ & $21(36.2)$ & $13(22.8)$ & $55(29.3)$ \\
\hline Surgical procedure & $3(3.1)$ & $0(0.0)$ & $0(0.0)$ & $3(1.6)$ \\
\hline Other & $8(8.2)$ & $13(22.4)$ & $2(3.5)$ & $22(11.7)$ \\
\hline Missing & 4 & 0 & 2 & 6 \\
\hline \multicolumn{5}{|l|}{ Type of bleed, $n(\%)$} \\
\hline Number of bleeds & 97 & 58 & 57 & 188 \\
\hline Target joint; all joint & II (II.3); 69 (7I.I) & 23 (39.7); 34 (58.6) & I4 (24.6); 42 (73.7) & 39 (20.7); I3। (69.7) \\
\hline Muscle & $12(12.4)$ & $6(10.3)$ & $\mathrm{I}(\mathrm{I} .8)$ & $19(10.1)$ \\
\hline External/skin & $\mathrm{I}(\mathrm{I} .0)$ & $\mathrm{I}(\mathrm{I} .7)$ & $0(0.0)$ & $2(I . I)$ \\
\hline Soft tissue & $13(13.4)$ & $17(29.3)$ & II (I9.3) & $32(17.0)$ \\
\hline Other ${ }^{a}$ & $18(18.6)$ & $16(27.6)$ & $9(15.8)$ & $37(19.7)$ \\
\hline Missing & 4 & 0 & 2 & 6 \\
\hline
\end{tabular}

Note: ${ }^{a}$ Other includes types of bleeds categorized as mouth/gums, nose, brain, and other. Abbreviation: ITT, immune tolerance therapy. 
from work or school in this study was the tracking and use of "eligible" diary days that reported a more realistic impact of bleeding on the interruption of planned work or school activities while highlighting the impact of the disease by demonstrating that about half the patients and caregivers were not routinely working or attending school. Disability and restricted physical independence are frequent developments in patients with hemophilia and could have deleterious effects on the employment of caregivers, particularly for those with more than one child with hemophilia. While this study was conducted throughout the calendar year and included young children (pre-elementary), and hence may have been partially confounded by school vacation periods and summer recess, the timing in relation to the school and daycare calendar is an important consideration for future studies aimed at collecting information of this nature. Furthermore, the high percentage of nonworking or non-school days is partly attributable to weekends and public holidays, a fact that should also be accounted for in future diary programs. Other measures that capture patient disability and the family burden of multiple children with $\mathrm{CHwI}$ could also be included in future questionnaires, including the expansion of the novel assessment of family activity changes, anxiety, and stress into a true caregiver burden scale.

The firewalled patient support liaison component (in which only contract research organization personnel had access to patient contact information) was critical to the success of this study, as it likely increased the diary completion rates and improved the quality of the results through frequent patient and caregiver contact from the dedicated patient support liaison personnel, who developed a good rapport with these participants. One limitation of this study was the small study population. It is unclear how many of the approximately $800 \mathrm{CHwI}$ patients in the United States have, on average, less than one bleeding episode per month and hence were excluded from this study. Although the diary completion rate was promising, a higher completion rate could have provided more comprehensive data. Another limitation was the fact that the majority of the patients were recruited from hemophilia treatment centers that had a larger patient pool and better resources to facilitate trials than others. These patients may not be representative of the majority of CHwI patients in the United States, and including patients from smaller treatment centers could have reduced the bias in the patient sample.

Although the objective of this article was to present and discuss the feasibility of daily diaries in CHwI patients, several points of interest deserve brief mention. (These topics will be discussed in greater detail in subsequent publications.) One is the higher percentage of bleed days and treatment days recorded in the ITT and prophylaxis groups, despite the fact that these data were only recorded on bleed days. A second observation is the similar distribution of bleed types and bleed locations among the on-demand, ITT, and prophylaxis groups, with spontaneous bleeds in the joints being the most common.

While our experience with the DOSE study proves the feasibility of obtaining patient-reported data in rare populations, the detailed analysis of primary and secondary endpoints from DOSE identifies issues that deserve further exploration through more focused patient-reported capture techniques. In an analysis of bleed symptoms and the reasons for initiating and discontinuing treatment, Valentino et $\mathrm{al}^{11}$ found that bleed resolution is difficult for adults and caregivers, particularly, to identify - an insight that might explain the sometimes longer treatment seen in observational studies than in clinical trials with fixed regimens. Comparing prescribed dosing with actual treatment, Young et $\mathrm{al}^{10}$ found that there was variability of patient dosing (dose, interval, and duration of treatment) compared with a single prescribed regimen for both children and adults, and identified the need to capture a range of recommended treatments for different scenarios in future studies. In looking at daily EQ-5D and pain data, Neufeld et $\mathrm{al}^{12}$ confirmed bleed (versus non-bleed) days and adult (versus pediatric) patients have worse HRQoL than non-bleed days, but identified that for adults with arthropathy, pain and HRQoL vary day to day, even without bleeds, challenging the paradigm of periodic QoL scores.

\section{Conclusion}

This study supports the feasibility and reliability of daily diary completion by CHwI patients and their caregivers. The data provides insight into the home treatment of these patients as well as the impact of hemophilia on patients and their families. A high diary-completion rate was facilitated by dedicated patient support personnel and motivated participants. One limitation of the electronic diary platform was the use of categorical responses to eliminate free text. Because the handwritten details recorded in the margins of paper diaries were crucial for identifying overlapping bleeds, a section for open-ended comments may improve the ease of future interpretation of electronic diaries. Detailed analysis of the results highlight the need to continue developing patientreported outcomes and caregiver instruments to continue exploring life with hemophilia. 


\section{Acknowledgments}

This study was supported by Novo Nordisk, Princeton, New Jersey, USA. The authors acknowledge the assistance of Outcome Sciences, Cambridge, Massachusetts, USA, which is the contract research organization that managed the DOSE study and analyzed the data under funding from Novo Nordisk Inc. The authors also recognize the medical writing and editorial assistance provided by Christina Soohoo, $\mathrm{PhD}$, a medical writer employed by Novo Nordisk Inc. The authors acknowledge the support of Novo Nordisk for data analysis and preparation of this manuscript.

\section{Disclosure}

GY and ASP received payment for consulting work for Novo Nordisk, Princeton, New Jersey, USA. DLC and RZG are employed by Novo Nordisk. CTS received grant support from Novo Nordisk for a pharmacoeconomics fellowship at the University of Illinois at Chicago. KH and JK were employed by Outcome Sciences, Cambridge, Massachusetts, USA.

\section{References}

1. Centers for Disease Control and Prevention. Blood Disorders. UDC Data Reports. https://www2a.cdc.gov/ncbddd/htcweb/UDC_Report/ UDC_Report.asp. Accessed June 18, 2012.

2. Darby SC, Keeling DM, Spooner RJ, et al. The incidence of factor VIII and factor IX inhibitors in the hemophilia population of the UK and their effect on subsequent mortality, 1977-1999. J Thromb Haemost. 2004;2(7):1047-1054.

3. Young G, McDaniel M, Nugent DJ. Prophylactic recombinant factor VIIa in haemophilia patients with inhibitors. Haemophilia. 2005;11(3): 203-207.

4. Roovers JP, van der Bom JG, van der Vaart CH, van Leeuwen JH, Scholten PC, Heintz AP. A randomized comparison of post-operative pain, quality of life, and physical performance during the first 6 weeks after abdominal or vaginal surgical correction of descensus uteri. Neurourol Urodyn. 2005;24(4):334-340.
5. Brown J, Thorpe H, Napp V, et al. Assessment of quality of life in the supportive care setting of the big lung trial in non-small-cell lung cancer. J Clin Oncol. 2005;23(30):7417-7427.

6. Puhan MA, Guyatt GH, Armstrong D, et al. Validation of a symptom diary for patients with gastro-oesophageal reflux disease. Aliment Pharmacol Ther. 2006;23(4):531-541.

7. Abrams P, Artibani W, Gajewski JB, Hussain I. Assessment of treatment outcomes in patients with overactive bladder: importance of objective and subjective measures. Urology. 2006;68 Suppl 2:17-28.

8. Van Kerrebroeck PE, Kelleher CJ, Coyne KS, Kopp Z, Brodsky M, Wang JT. Correlations among improvements in urgency urinary incontinence, health-related quality of life, and perception of bladder-related problems in incontinent subjects with overactive bladder treated with tolterodine or placebo. Health Qual Life Outcomes. 2009;7:13.

9. Haiderali A, Menditto L, Good M, Teitelbaum A, Wegner J. Impact on daily functioning and indirect/direct costs associated with chemotherapy-induced nausea and vomiting (CINV) in a U.S. population. Support Care Cancer. 2011;19(6):843-851.

10. Young G, Shapiro AD, Walsh CE, Gruppo RA, Gut RZ, Cooper DL. Patient/caregiver-reported recombinant factor VIIa (rFVIIa) dosing: home treatment of acute bleeds in the Dosing Observational Study in Hemophilia (DOSE). Haemophilia. 2012;18(3):392-399.

11. Valentino LA, Walsh CE, Reding MT, Young GA, Levendoglu-Tugal O, Cooper DL. Patient- and caregiver-reported bleeding symptoms and reasons for starting and stopping treatment with recombinant factor VIIa: analysis of the Dosing Observational Study in Hemophilia (DOSE). Haemophilia. 2012;18(4):554-560.

12. Neufeld EJ, Recht M, Sabio H, et al. Effect of acute bleeding on daily quality of life (QOL) assessments in patients with congenital hemophilia with inhibitors and their families: observations from the Dosing Observational Study in Hemophilia (DOSE). Value Health. 2012;15(6):916-925.

13. World Medical Association Declaration of Helsinki: ethical principles for medical research involving human subjects. http://www.wma.net/ en/30publications/10policies/b3/. Accessed June 18, 2012.

14. Guidelines for good pharmacoepidemiology practices (GPP). Pharmacoepidemiol Drug Saf. 2008;17(2):200-208.

15. Love L. Home therapy forms - why don't they come back? Haemophilia. 1996;2 Suppl 1:48.
Journal of Blood Medicine

\section{Publish your work in this journal}

The Journal of Blood Medicine is an international, peer-reviewed, open access, online journal publishing laboratory, experimental and clinical aspects of all topics pertaining to blood based medicine including but not limited to: Transfusion Medicine; Blood collection, Donor issues, Transmittable diseases, and Blood banking logistics; Immunohematology; Artificial and alternative

\section{Dovepress}

blood based therapeutics; Hematology; Biotechnology/nanotechnology of blood related medicine; Legal aspects of blood medicine; Historical perspectives. The manuscript management system is completely online and includes a very quick and fair peer-review system. Visit http://www.dovepress.com/ testimonials.php to read real quotes from published authors. 